\title{
Epistemic contextualism and linguistic behavior
}

\section{Document Version}

Accepted author manuscript

Link to publication record in Manchester Research Explorer

\section{Citation for published version (APA):}

Buckwalter, W. (2017). Epistemic contextualism and linguistic behavior. In J. Jenkins Ichikawa (Ed.), The Routledge Handbook of Epistemic Contextualism (1st ed., pp. 44-56). Routledge.

https://www.taylorfrancis.com/books/e/9781315745275

\section{Published in:}

The Routledge Handbook of Epistemic Contextualism

\section{Citing this paper}

Please note that where the full-text provided on Manchester Research Explorer is the Author Accepted Manuscript or Proof version this may differ from the final Published version. If citing, it is advised that you check and use the publisher's definitive version.

\section{General rights}

Copyright and moral rights for the publications made accessible in the Research Explorer are retained by the authors and/or other copyright owners and it is a condition of accessing publications that users recognise and abide by the legal requirements associated with these rights.

\section{Takedown policy}

If you believe that this document breaches copyright please refer to the University of Manchester's Takedown Procedures [http://man.ac.uk/04Y6Bo] or contact uml.scholarlycommunications@manchester.ac.uk providing relevant details, so we can investigate your claim.

\section{OPEN ACCESS}




\title{
Epistemic Contextualism and Linguistic Behavior*
}

\author{
Wesley Buckwalter \\ wesleybuckwalter@gmail.com
}

\begin{abstract}
Epistemic contextualism is the theory that "knows" is a context sensitive expression. As a linguistic theory, epistemic contextualism is motivated by claims about the linguistic behavior of competent speakers. This chapter reviews evidence in experimental cognitive science for epistemic contextualism in linguistic behavior. This research demonstrates that although some observations that are consistent with epistemic contextualism can be confirmed in linguistic practices, these observations are also equally well explained both by psychological features that do not provide support for contextualism and by rival theories that are inconsistent with contextualism. I conclude that the motivation for epistemic contextualism is underdetermined by existing experimental evidence, yielding little reason to accept it as an account of our actual linguistic practices.
\end{abstract}

Keywords: social cognition; knowledge; intuition; evidence; epistemic standards

* This is the penultimate version of a paper to appear in J. J. Ichikawa (Ed.), The Routledge Handbook of Epistemic Contextualism. Please cite the final, published version. 
Any statement can be held true come what may, if we make drastic enough adjustments elsewhere in the system. - Willard Van Orman Quine

\section{Introduction}

Epistemic contextualism is the linguistic theory that the word "knows" is context sensitive (Lewis 1996; DeRose 2009; Cohen 2013). The theory states that the standards that are required in order to truthfully say a person knows a proposition are set by and shift according to the contexts in which that statement is made. This view is primarily motivated by claims about the linguistic behavior of competent speakers. More specifically, epistemic contextualism is motivated by the claim that it offers the best explanation of observable facts about the use of "knows" in certain cases. According to this theory, for example, people truthfully say both, "I know the bank is open tomorrow," and "I do not know the bank is open tomorrow" when the standards required in order to "know" shift between those contexts. Many things could potentially shift standards between contexts. Two specific contextual features are often discussed. One feature involves practical consequences, for example, whether the stakes associated with the bank being closed for the ascriber are low or high. Another feature involves error salience, for example, whether or not uneliminated possibilities of error are made apparent to the ascriber. Contextualists claim that competent speakers behave in these ways, and that the fact that they do this is "evidence of the very best type that one can have for concluding that any piece of ordinary language is context-sensitive" (DeRose 2005: 172, see also Pynn, this volume).

This chapter reviews evidence in experimental cognitive science for epistemic contextualism in linguistic behavior, focusing on three questions. First, has experimental 
observations confirmed that the behavioral patterns motivating epistemic contextualism in ordinary language are real? Second, does the existence of these behavioral patterns constitute a sufficient reason to accept epistemic contextualism as an explanation of them over other explanations of them? Third, does epistemic contextualism explain specific linguistic behaviors involving skepticism any better than other theories do, given what has been discovered about the psychological origins of skepticism in cognitive science?

To anticipate the answers to these questions, first, experimental evidence for epistemic contextualism is mixed. Many studies have found evidence that is inconsistent with the motivation for epistemic contextualism, while other studies have found evidence consistent with it. Second, while evidence has been found that is consistent with epistemic contextualism, these results are also equally well explained both by psychological features that do not provide any evidence for contextualism and by rival theories of "knowledge" that are inconsistent with contextualism. Third, experimental research on the origins of skepticism suggests that the theory of epistemic contextualism does not explain certain skeptical patterns observed in ordinary language any better than rivals do. I conclude that despite over thirty years of theoretical developments in philosophy and five years of experimental testing in cognitive science, epistemic contextualism remains underdetermined by existing experimental evidence, yielding little motivation to accept it as an account of our actual linguistic practices.

\section{Mixed Linguistic Evidence}

Epistemic contextualism is primarily motivated by empirical claims about linguistic behavior of competent speakers in certain situations. One claim is that we find a 
knowledge-ascribing sentence (e.g. "S knows that p") and its denial (e.g. "S does not knows that p") to both be true when the evidential standards set by the context in which they are made shift from low to high. A second claim is that we find the same knowledge-ascribing sentence (e.g. "S knows that p") to be true when the evidential standards set by the context are low and false when the evidential standards set by the context are high. The motivation for contextualism is that the theory can explain these behaviors. But do competent speakers actually behave in these ways? This section reviews studies that have found mixed experimental evidence regarding the motivation for epistemic contextualism in linguistic behavior.

Several studies have detected patterns of responses that challenge the motivation for epistemic contextualism (Buckwalter 2010, 2014; Feltz and Zarpentine 2010; see also May, Sinnott-Armstrong, Hull, and Zimmerman 2010). They have done so by examining stimuli identified by contextualists as the best thought experiments for testing the view that "knows" is a context sensitive expression (though see DeRose 2011 for criticism). In one experiment for instance, Feltz and Zarpentine (2010: Experiment 1) presented participants with one of two bank cases manipulating the context in which a knowledge sentence was made. One story featured low practical consequences and error salience:

Hannah and her wife Sarah are driving home on a Friday afternoon. They plan to stop at the bank on the way home to deposit their paychecks. It is not important that they do so, as they have no impending bills. But as they drive past the bank, they notice that the lines inside are very long, as they often are on Friday afternoons. Realizing that it isn't very important that their paychecks are deposited right away, Hannah says, 'I know the bank will be open tomorrow, 
since I was there just two weeks ago on Saturday morning. So we can deposit our paychecks tomorrow morning'. (Feltz and Zarpentine 2010: 703)

The other story featured high practical consequences and error salience:

Hannah and her wife Sarah are driving home on a Friday afternoon. They plan to stop at the bank on the way home to deposit their paychecks. Since they have an impending bill coming due, and very little in their account, it is very important that they deposit their paychecks by Saturday. Hannah notes that she was at the bank two weeks before on a Saturday morning, and it was open. But, as Sarah points out, banks do change their hours. Hannah says, 'I guess you're right. I don't know that the bank will be open tomorrow'. (ibid)

Participants in both conditions were instructed to "Assume that the bank really will be open tomorrow." Participants in the Low Context condition were then asked how strongly they agreed or disagreed that "When Hannah says, "I know the bank will be open tomorrow,', what she says is true." Alternatively, participants in the High Context condition were asked how strongly they agreed or disagreed that "When Hannah says, "I don't know the bank will be open tomorrow," what she says is true." Participants evaluated these statements on a seven-item agreement scale, where "1" was anchored with "strongly agree", "4" anchored with "neutral", and "7" with "strongly disagree".

Researchers found that participants were ambivalent about the truth of both knowledge sentences. The mean response was 3.74 in high context (or 4.26 after this score was reverse-coded to approximate knowledge ascription) and 3.68 in low context. Contextualism is motivated by the claim that competent speakers find these kinds of knowledge-ascribing and knowledge-denying sentences to both be true. In actuality, 
participants did not display this tendency. Participants remained neutral about the truth of both of these sentences. They reacted to these sentences using the neutral mid-point of the scale, or at about the level of chance. Researchers replicate this same basic pattern of results across a series of different cover stories.

Researchers have also found evidence that does not support contextualism when examining evaluations of the same knowledge-ascribing sentence across different contexts (Buckwalter 2010). In this study, by Buckwalter, participants were presented with three variations on the bank case above. The first case, Bank, involved a situation in which practical consequences and error salience were low. The second case, High Stakes, involved an adaptation in which error salience was low and practical consequences were high (e.g. "Bruno has written a very large check, and if the money from his pay is not deposited by Monday, it will bounce, leaving Bruno in a very bad situation with his creditors," p. 401) The third case, High Salience, involved low practical consequences and high error salience in which a character challenges a speaker's claim (e.g. "Sylvie says, "Banks are typically closed on Saturday. Maybe this bank won't be open tomorrow either. Banks can always change their hours, I remember that this bank used to have different hours."). Participants were then instructed, "On a scale of 1 to 5, circle how much you agree or disagree that Bruno's assertion, "I know the bank will be open on Saturday" is true."

Participants tended to agree that Bruno's knowledge statement was true in all three cases. The mean in Bank was 3.83. The mean in High Stakes was 3.71. The mean in High Salience was 3.64. All three means were significantly greater than the midpoint of this scale, or greater than chance rates. Contextualism is motivated by the idea that the 
knowledge-ascribing sentence is more likely to be true in High Stakes or Salience than in Bank. In actuality, participants did not display this tendency. Participants tended to think that Bruno spoke truthfully in all three cases, despite the changes in context.

Researchers have also found evidence that challenges contextualism when directly asking participants to evaluate evidential standards across contexts (Turri 2016: Experiment 4). In one study, for instance, participants were presented with cases involving either low practical consequences and error salience or high practical consequences and error salience similar to those used in prior research. However instead of making a claim about knowledge, both stories end with a character asking a question about the standards of evidence required to know:

"Jane continues, "This actually raises a more general question I've been considering. On a scale of 1 to 10 , with 10 being the highest, how strong must your evidence be in order to know that the bank is open tomorrow?" (p. 11)

Participants were then instructed to enter a value from one to ten in the following sentence, "Knowing requires evidence that rates on the scale."

Context did not significantly impact people's answers about the evidential standards. The mean response was 8.6 in high context and 8.3 in low context. Contextualism is motivated by the idea that the evidence required to truthfully say someone knows something increases as the context shifts from low to high. In actuality, participants did not display this tendency. Participants selected the same standard of evidence in both low and high Context. In other words, ordinary speakers did not acknowledge any shifting evidentiary standards across these contexts. 
Lastly, researchers have also found evidence unfavorable to contextualism in related judgments about knowledge ascription (May, Sinnott-Armstrong, Hull, and Zimmerman 2010). In these studies, participants were presented with one of four bank cases that independently varied both practical consequences and error salience. In all four cases, the protagonist claims to know the bank will be open. Participants were then asked to agree or disagree with the statement that the protagonist knows that the bank will be open. They found that participants tended to agree that the protagonist knew in each case. Researchers also found a small main effect whereby overall agreement with the ascription was less pronounced when the stakes were high than low. This study is different from the studies above in that it collects judgments about knowledge ascription (i.e. "Hannah knows") rather than assessments of the truth-value of knowledge-ascribing sentences (i.e. "the expression 'Hannah knows' is true"). As a result of this, some have argued that these findings "have no tendency to jeopardize the kinds of intuitions generally used to support standard forms of contextualism" (DeRose 2011: 83). That said, to the extent these judgments are regularly related in ordinary practice, the results do not instill much confidence in the motivation for the theory.

While this body of evidence challenges the motivation offered for epistemic contextualism, there are also limitations to this evidence. On the one hand, subtle features of the stimuli or probing could be obscuring contextualist friendly results yet to be discovered. Perhaps the particular manipulations used involving stakes or error salience were insufficient to effectively shift the conversational context that, in turn, is supposed to affect our evaluations (see Schaffer and Knobe 2012). Moreover, it could be that there are other, more effective factors that shift contextual standards of evidence beyond error 
salience or practical consequence yet to be discovered. On the other hand, it is important not to underestimate the significance of the present evidence. People said knowledge sentences were true in contexts where they were supposed to find them false, and did not say they were true in contexts where they were supposed to do that. Neither did judgments about the amount of evidence required to "know" provide any reason to think evidential standards shifted across low and high conversational contexts. If other factors beyond error salience or practical consequences shift evidentiary standards, then the burden clearly falls on contextualists to identify and characterize them.

Despite the initial evidence detected by several independent teams of researchers challenging the motivations of epistemic contextualism, some researchers have found evidence that the motivation for it is real (Hansen and Chemla 2013). These researchers conducted a complex within-subjects experiment designed to test whether shifts in conversational context impact the standards of evaluation of several types of sentences. They studied whether there were contextualist patterns detectable for "knows". As an interesting point of comparison, they also studied whether there were contextual effects for other sorts of words such as something being "green" or "beige". To do this, researchers manipulated four factors. The first factor was the Type of Scenario: Knowledge, Color, or Miscellaneous. Participants in the Knowledge condition saw stories and evaluated sentences about "knows" (e.g. "I know the bank will be open tomorrow"). Participants in the Color condition saw stories and evaluated sentences about color terms like "beige" or "green" (e.g. "The walls in our apartment are beige"). Participants in the Miscellaneous condition saw stories and evaluated sentences about disparate items (e.g. "There is milk in the refrigerator"). The second factor was Cover 
Story. Researchers devised four cover stories within the Knowledge condition, four cover stories within the Color condition, and two cover stories within the Miscellaneous condition. This resulted in ten basic cover stories. The third factor was Context. The Context factor manipulated whether the salience of error possibilities was low or high. The fourth factor was Polarity. The Polarity factor manipulated whether or not the protagonist in each cover story made a positive or a negative claim about "knowledge", "color", or the "miscellaneous" item involved in that particular story.

This resulted in 40 conditions (ten basic cover stories, each of which could have a low or high context, and each of which featured a statement with positive or negative polarity). Forty participants were each given all 40 conditions presented in four set orders or "blocks". After seeing each one of these forty cases, researchers asked participants to rate whether or not what the protagonist in the story said about the presence or absence of "knowledge", "color", or the "miscellaneous" item was true. Participants could answer on a number line ranging from "false" to "true" in which values of $0-100 \%$ were possible.

Researchers found evidence supporting the existence of shifting contextual standards in the Knowledge, Color, and Miscellaneous conditions. Collapsing across all the cover stories within these conditions, there was a significant interaction effect between Context and Polarity for each type of sentence. Participants were more likely to think that positive statements (e.g. "I know the bank will be open tomorrow" or "The walls in our apartment are beige") were true when the context was low than when it was high. And they were more likely to think that negative statements (e.g. "I don't know the bank will be open tomorrow" or "The walls in our apartment aren't beige.") were true when the context was high than when it was low. These results are visualized in Figure 1. 


\begin{tabular}{|c|c|c|c|}
\hline$\oplus \quad \begin{array}{c}\text { Kow } \\
\text { High }\end{array}$ & Color & Miscellaneous \\
\hline $\begin{array}{c}\text { Statistical diff. } \\
\ominus \text { Low }\end{array}$ & $F(1,38)=24, p<.001$ & $F(1,38)=41, p<.001$ & $F(1,38)=55, p<.001$ \\
\hline $\begin{array}{r}\text { High } \\
\text { Statistical diff. }\end{array}$ & $F(1,38)=4.6, p=.05$ & $F(1,38)=38, p<.001$ & $F(1,38)=38, p<.001$ \\
\hline Stat. interaction & $F(1,38)=17, p<.001$ & $F(1,38)=49, p<.001$ & $F(1,38)=61, p<.001$ \\
\hline
\end{tabular}

Figure 1. Mean scores to the dependent variable collapsing across all cover stories in Knowledge, Color, or Miscellaneous conditions. Positive Polarity is indicated by “+”, negative by "_.". Context is indicated by "Low" and "High". Reprinted from Hansen and Chemla (2013) with permission.

Results confirm that people say that these knowledge-ascribing sentences are true in low contexts and knowledge-denying sentences are true in high contexts. Incidentally, researchers also found evidence of similar patterns for color terms and other miscellaneous items in ordinary language. However some aspects of this experiment also question how strongly the results support epistemic contextualism. First, there was a three-way interaction effect between Type of Scenario, Context, and Polarity. The contextual effects for "knows" were weak in comparison to those readily exhibited for color terms or other miscellaneous items in the study like being "beige". Second, despite the small interaction effect between Context and Parity in Knowledge conditions, participants also simply agreed that knowledge sentences were true across the board. Overall, the general tendency was to answer that knowledge-ascribing sentences were still true even in high standards contexts and that knowledge-denying sentences were still true in low standards contexts. This begins to question the unique role of context in these 
matters over and above the presence of simple agreement bias or default trust in testimony that might occur regardless of shifting standards (see Turri 2016; Hansen and Chemla 2013: 309 for discussion). Third, the contextual effects observed for "knows" could be due to task demands of the experiment (though see Hansen 2014). The results reported in Figure 1 represent within-subjects comparison in which participants saw all versions of each cover story. However researchers obtained different results when they reanalyzed the data at a time-point in which each participant had only seen one version of each cover story. When participants had only seen one version of each story, contextual effects in Color and Miscellaneous were found, but contextual effects in Knowledge were not found. This suggests that the contextual pattern detected for "knows" may be the result of ordering and exposure to other items in the experiment.

Lastly, some researchers have found evidence that supports contextualism in related judgments about knowledge ascription (Alexander, Gonnerman, and Waterman 2014; see also Buckwalter and Schaffer 2015; Waterman, Gonnerman, Yan, and Alexander in press, for replication and cross cultural variation). These researchers presented participants with two vignettes developed by Nagel (2010) varying the salience of error possibilities about seeing a red object. Here is the Low Context case:

John A. Doe is in a furniture store. He is looking at a bright red table under normal lighting conditions. He believes the table is red.

The High Context case included the low context story and the following addition:

However, a white table under red lighting conditions would look exactly the same to him, and he has not checked whether the lighting is normal, or whether there might be a red spotlight shining on the table. 
Alexander, Gonnerman, and Waterman then asked participants whether they agreed or disagreed with the claim that John knows that the table is red. Participants answered on a six-item agreement scale with " 1 " anchored "strongly disagree" and "6" anchored "strongly agree". They found a large effect between these conditions. Although participants tended to attribute knowledge in both conditions, this tendency was much more pronounced in Low Context (mean response of 5.5) than High Context (mean response of 3.8).

These results are also friendly to contextualism, with three important caveats. First, as noted above, the result technically does not directly test epistemic contextualism since it measures rates of knowledge ascription rather than evaluation of the truth of knowledge-ascribing sentences. But again, to the extent these judgments are closely related, the results are consistent with contextualist claims. Second, despite the large effect of condition on responses, knowledge was attributed in Low and High Context across the board. Third, the experimental and control conditions are not minimally matched pairs. It is possible that wording effects concerning the quality of the initial evidence (e.g. "he has not checked") or large differences in length (i.e. a difference of 37 words) and complexity of stimuli impact responses in unforeseen ways orthogonally to manipulating the contextual standard.

\section{Underdetermined by Evidence}

Although support for epistemic contextualism is mixed, some ordinary language practices consistent with the motivation for epistemic contextualism have been found. These 
findings constitute evidence that the motivation for it is real. But does this evidence provide a good reason to accept contextualism over rival theories?

Confirmation of empirical predictions does not always constitute good evidence to accept one theory over a rival theory. One example of this from the history of science is illustrative. Ancient theories of Copernican and Ptolemaic astronomy are rival theories of celestial bodies. Before the invention of the telescope however, these rival theories both successfully predicted the positions of planets and many stars as seen by the naked eye (Kuhn 1962: 68). The observable facts collected up until that point supported both rivals. Thus there was little reason to accept the Copernican theory over the Ptolemaic theory until the invention of the telescope allowed for observations of a domain in which these theories made different predictions.

Supposing some behaviours said to motivate epistemic contextualism in ordinary language can be empirically confirmed, the question now becomes whether or not this provides a sufficient reason to prefer epistemic contextualism to rival invariantist theories denying that evidentiary standards are set or shift due to conversational context. Like the case of Ptolemaic and Copernican astronomy, theory choice would be underdetermined if the claims epistemic contextualism makes about linguistic practices can also be explained even if epistemic contextualism was false. In that case, confirming the empirical predictions of epistemic contextualism would not provide a sufficient reason to accept it over invariantism. Researchers have confirmed that this is in fact the case, by showing that the predictions of epistemic contextualism can be found even if contextualism is false. 
One recent study examined whether or not epistemic contextualism can explain patterns of responses in classic bank cases any better than rival theories can (Turri 2016: Experiment 1; see also Dinges 2015, for discussion). Participants were presented with one of two closely matched bank case vignettes. One case was a low stakes low error salience variant in which a protagonist Keith attributes knowledge to himself that the bank will be open tomorrow. The other was a high stakes high error salience variant in which Keith denies that he knows the bank will be open. After seeing one of these two cases, participants were asked to rate their agreement with a series of test items, such as that "It's true that the bank is open tomorrow", "Keith believes that the bank is open tomorrow", "Keith has good evidence that the bank is open tomorrow", "Keith should come back tomorrow morning instead", and "When Keith said, 'I [do/don't] know,' what he said was true", respectively.

The result was that predictions made by epistemic contextualism were true. Participants in the low stakes condition tended to agree that Keith truthfully said he knew in the low stakes case. Participants in the high stakes condition also tended to agree that Keith truthfully said he did not know. However there were also found large differences in the way participants evaluated the other epistemic details of the cases. More specifically, participants were much more likely to agree that it was true the bank was open tomorrow, that Keith had good evidence for this, believed this, and should act in a way that makes sense given the bank is open in the low stakes case than in the high stakes case.

These results are consistent with epistemic contextualism but do not give us a good reason to accept it. Most philosophers agree that knowledge requires justified true belief. So it is perhaps unsurprising that competent speakers evaluate "knowledge" expressions 
differently as judgments concerning the quality of the evidence a protagonist has, what a protagonist believes, or what is likely to be true each fluctuate between stories. If these things fluctuate between stories, then there is no need to postulate the existence of shifting standards to explain "knowledge" judgments in low and high cases. Such judgments can easily be explained even if contextualism is false by more traditional theories of knowledge.

Patterns of responses are also equally well explained by rival theories that postulate a connection between knowledge and action (see Fantl and McGrath 2009; Hawthorne and Stanley 2008; Turri and Buckwalter Forthcoming). If truthfully saying a person "knows" something depends partially on whether they can act on a belief, and actionability is being evaluated differently between stories, then neither is there a need to posit the existence of shifting standards to explain why "knowledge" judgments fluctuate between cases. In short, this evidence suggests that many things are actually not being held fixed when we psychologically process these thought experiments and make judgments about them. The fact that other variables shift during the process of evaluation undermines the motivation for epistemic contextualism. The fact that this happens also questions the support for contextualism offered elsewhere in the experimental literature that does not control for the possibility of other shifting epistemic variables.

Researchers have also demonstrated that some contextualist friendly intuitions are the result of confounds in contextualist thought experiments and experimental stimuli. When constructing test cases, contextualists continually insist that the best evidence for their view comes from comparing judgments about knowledge-ascribing sentences in low contexts and knowledge-denying sentences in high contexts (DeRose 2005: 173; 2009: 
50; 2011: 86). But one hypothesis is that our reactions to such sentences reflect basic aspects of the psychology of self-attribution that have nothing to do with contextual standards. More specifically, it could be that participants find knowledge-ascribing and knowledge-denying sentences true despite low or high contexts simply because we tend to defer to what other people say about the state of their own knowledge. If participants evaluate these sentences on the basis of deference, then the fact that people find knowledge-ascribing and denying sentences true in different contexts does not provide good evidence for the existence of shifting contextual standards. The same pattern of responses could just as well be explained by deference even if epistemic contextualism is false.

To test whether or not deference confounds contextualist thought experiments, a separate group of participants were presented with one of two simple bank case variations (Turri 2016: Experiment 2). Both variations featured identical low stakes contexts in which the salience of error was low. The only difference between them was that in one case the protagonist self-attributed knowledge to himself that the bank will be open, while in the other case the protagonist self-denied that knowledge. After seeing one of these cases, participants were then asked the same questions as in the prior experiment. The result was that "knowledge" judgments were highly deferential. Participants in the self-ascription condition tended to agree that the protagonist truthfully said he knew in the low standards case. And participants in the self-denial condition also tended to agree that the protagonist spoke truthfully when he said he did not know that. In other words, the exact pattern of results used to motivate epistemic contextualism can be obtained in the same bank cases where no shifts in stakes or error salience occurred. Subsequent 
experiments further revealed that contextualist patterns in low and high cases disappeared when steps were taken to control for deference (Turri 2016: Experiment 3; see also Buckwalter 2014; Hansen and Chemla 2013, for evidence of this).

These findings strongly suggest that responses in classic bank cases taken to motivate contextualism are associated with features that have nothing to do with shifting contextual standards. Some contextualists have argued that the pressure to accommodate utterances is itself a factor that can shift contextual standards (Lewis 1979; DeRose 2011: 88). The present results do not rule out this possibility. However, the propensity to defer to what people say about their own mental states can also explain these patterns regardless of the presence of context-sensitive terms. Indeed it is a far simpler explanation than the positing of context-sensitive linguistic expressions. In any event, the fact that people tend to find these knowledge-ascribing and denying sentences true provides no unique motivation for contextualism over other psychological explanations. This also raises the possibility that the construction of contextualist-friendly thought experiments, and in turn, the intuitions motivating the theory, have been confounded by this psychological tendency from the start.

\section{Doubtful Theoretical Advantage}

When theory choice between rival theories is underdetermined, the evidence does not provide sufficient reason to select one theory over another. However some philosophers of science have argued that we can still have good reasons to prefer one theory to another when this happens. For example, we might prefer one theory to another because that theory is simpler, more explanatory, or more cohesive with other theories we accept 
(Quine 1955; Laudan and Leplin 1991). In the present case, observations of linguistic behavior do not sufficiently motivate epistemic contextualism. But perhaps there are other reasons why one might accept the theory over rivals.

Some philosophers have argued that contextualism is preferable to rival theories because it provides theoretical solutions to skeptical problems like brain-in-the-vat scenarios or the lottery paradox (Cohen 1998; Lewis 1996; Hannon this volume; see also Benton this volume). According to this solution, shifting evidential standards set by conversational context explain why one can truthfully say one knows something in everyday contexts, and truthfully deny one knows something when error possibilities in BIV or lottery odds become salient. This itself, of course, is not evidence that the theory is true. With respect to skepticism, for example, Keith DeRose writes that the contextualist solution would be "unmotivated and ad hoc" without an independent reason to think evidentiary standards do shift in non-philosophical usage (DeRose 2002: 169; see also Rysiew 2011, for discussion). It is doubtful that the relevant shifts in nonphilosophical talk have been adequately shown. Nonetheless, the ability to offer solutions to theoretical puzzles that rival theories potentially cannot is one incentive to accept it over those rivals.

Research in experimental cognitive science suggests that contextualism does not explain skepticism any better than rival theories do (Turri 2014; Turri and Friedman 2014). With respect to lottery problems, for instance, research suggests that skeptical judgments are probably not the product of shifting contexts involving the salience of error. In illustrating this point, researchers devised two lottery thought experiments in which high error possibilities were salient (Turri and Friedman 2014: Experiment 5). The 
cases differed only in one small respect. One version involved the chances of winning a formal lottery, while the other involved the chances of finding a lucky combination of numbers:

Abigail is talking with her neighbor, Stan, who is a statistician. Stan hands Abigail a bill and says, "Here is the ten dollars I owe you." Abigail looks at the bill and sees that its serial number is 5-0-6-7-4-1-6-9-8-2. Stan continues, "I made an interesting calculation. That serial number is just as likely to be Brad Pitt's mobile phone number as it is to win this week's lottery." Abigail answers, "That combination [will not win this week's lottery/is not Brad Pitt's mobile number]." And Abigail was exactly right: that combination [was a loser/it was not Brad Pitt's number]. (Turri and Friedman 2014: 61-62)

When researchers presented these cases to hundreds of participants, they found that people were more likely to agree that Abigail knows the combination was not Brad Pitt's number than it was a loser in the lottery. These results support the assumption that people are skeptical about formal lottery cases. However the results do not support the idea that this skepticism is explained by shifting evidential standards. People were more skeptical about formal lotteries than informal ones in conversational contexts with identical error salience. On the basis of this observation, Turri and Friedman suggest that lottery intuitions are, at least in part, due to formulaic responses, habituation, or familiarity with formal lotteries specifically. While researchers continue to investigate what factors might underlie formulaic expressions about formal lotteries, the results indicate that intuitions are probably not explained by shifting evidential standards any better than rival theories explain them. 
Related research on error salience and the origins of skeptical judgments more generally suggests that skepticism could be the result of several different types of cognitive biases involving "epistemic egocentrism" (Nagel 2010), "focal bias" (Gerken 2013), or the "source-content bias" (Turri 2014). According to the source-content bias theory, for example, the appeal of skepticism results from considering a particular combination of claims. More specifically, the theory postulates that classical skeptical arguments prey on negative claims made on the basis of inferential sources of evidence. Researchers demonstrated this bias exists in the following experiment (Turri 2014: Experiment 1). The experiment independently manipulated whether the Source of a belief was perceptual or inferential. It also manipulated whether the Content of the belief involved a positive claim about something being present or a negative claim about something being absent. The four resulting cases were as follows:

Michelle has visited the city zoo every day for the past ten years. Her favorite exhibit is The Big Cat Exhibit. Over thousands of observations, the animal in this exhibit has always been a jaguar. Today [Michelle must stay home and can't visit the zoo because she sprained her ankle. While relaxing on the couch/when Michelle left home to visit the zoo, she almost sprained her ankle. While looking at the animal in the exhibit], Michelle thinks, "The animal in the Big Cat Exhibit today is [a jaguar/not a leopard]." And she is right: it is [a jaguar/not a leopard]. (Turri 2014: 313)

Participants were then asked to indicate whether Michelle "knows" or "only believes" that the animal is a jaguar, or not a leopard, respectively. 
Participants were much more likely to deny knowledge both when a source was inferential rather than perceptual and when the claim was negative rather than positive. Moreover, a large interaction effect was found whereby participants were much more likely to deny knowledge in negative inferential cases than in positive inferential cases. In other words, participants were especially prone to embrace skepticism about negative inferential claims. These results are visualized in Figure 2.

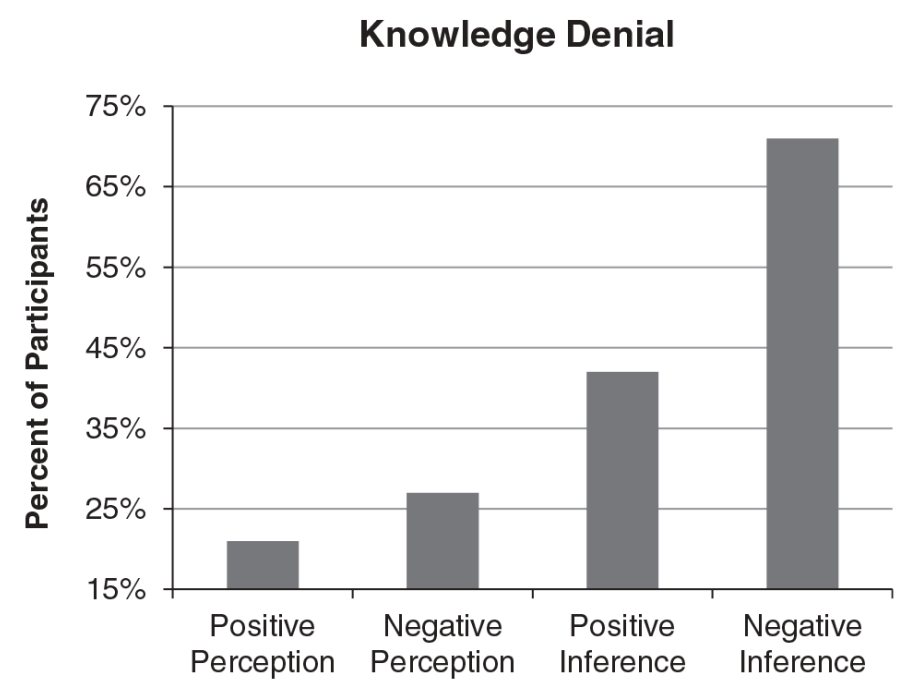

Figure 2. Rates of knowledge denial across conditions. Reprinted from Turri (2014) with permission.

The source-content bias may begin to explain why it appears to us that one can truthfully say one knows something in everyday contexts and deny this in extremely skeptical contexts. More specifically, it could be that we are likely to find certain utterances such as "I don't know I'm not a brain in a vat," to be truthful because they are negative and inferential, while we are also likely to view other utterances, such as "I know that I have hands," to be truthful because they are positive and perceptual. In that case, there would 
be no need to posit shifting standards to explain why those utterances both seem truthful to us. Assuming that biased judgments are less likely to be true than un-biased ones, this hypothesis may also begin to provide an alternative philosophical response to skepticism than epistemic contextualism does. According to this hypothesis, certain knowledgedenying sentences paradigmatic of extreme skepticism such as "I don't know I'm not a brain in a vat" are likely false because they are the product of bias. Researchers continue to investigate the interaction between these factors and the degree to which this can satisfactorily explain a variety of different skeptical reactions (for critical discussion, see Gerken Forthcoming). For present purposes, however, the availability of alternative theories strongly questions the idea that contextualism offers a unique theoretical advantage regarding skepticism.

\section{Conclusion}

Epistemic contextualism is a linguistic theory that is answerable to observable facts about linguistic behavior. The debate over this theory is well into its third decade without clear experimental evidence that the motivation for it is real or compelling. Many researchers have found evidence that challenges these motivations. Some researchers have found evidence that supports them. However these results can also be explained even if contextualism is false. For example, it has been demonstrated that shifting between contexts influences other epistemic variables that can explain "knowledge" judgments. There are confounds in thought experiment construction which yield contextualist friendly intuitions that may have nothing to do with shifting standards. Moreover, it is doubtful that epistemic contextualism has other decisive theoretical advantages, such as 
being uniquely positioned to explain skeptical judgments in ordinary language. This body of evidence significantly questions the motivation for the theory and does not provide a good reason to accept it as an account of our linguistic practices.

In the case of Copernican and Ptolemaic astronomy, theory choice was eventually made possible by the advancements of scientific instruments, allowing for new observations in which the theories made rival predictions. Moving forward, a similar solution may aid theory selection in epistemology. The main instruments used thus far have involved intuition, introspection, and social observation. Testing in experimental cognitive science can improve upon these instruments. In several cases, this approach has already begun to do so, by providing growing evidence for invariantist theories in ordinary language (Powell, Horne, Pinillos, and Holyoak 2015; Pinillos 2012; Turri, Buckwalter, and Rose 2016; Turri and Buckwalter Forthcoming). However such testing has not produced compelling evidence for contextualism. This leads one to wonder how long research programs in epistemic contextualism can continue before practitioners deliver clear and concrete experimental evidence that the patterns of linguistic behavior that motivate it are real, cannot be explained in psychological rather than semantic terms, or by other theories inconsistent with contextualism.

Acknowledgements - For helpful feedback I thank James Beebe, Nathan Cockram, Mikkel Gerken, Michael Hannon, Jonathan Jenkins Ichikawa, Robert Stainton, and John Turri. This research was supported by a Banting Fellowship awarded through the Social Sciences and Humanities Research Council of Canada. 
Biographical note: Wesley Buckwalter is a Banting Fellow in the Department of Philosophy at the University of Waterloo.

\section{References}

Alexander, Joshua, Gonnerman, Chad, and Waterman, John (2014), 'Salience and Epistemic Egocentrism: An Empirical Study', in James Beebe (ed.), Advances in Experimental Epistemology (Bloomsbury), 97-118.

Benton, M A (this volume), 'Lotteries and Prefaces', in Jonathan Ichikawa (ed.), Handbook of Epistemic Contextualism (Routledge).

Buckwalter, Wesley (2010), 'Knowledge Isn't Closed on Saturday: A Study in Ordinary Language', Review of Philosophy and Psychology, 1 (3), 395-406.

--- (2014), 'The Mystery of Stakes and Error in Ascriber Intuitions', in James Beebe (ed.), Advances in Experimental Epistemology (Bloomsbury), 145-74.

Buckwalter, Wesley and Schaffer, Jonathan (2015), 'Knowledge, stakes, and mistakes', Nous, 49 (2), 201-34.

Cohen, Stewart (1998), 'Contextualist solutions to epistemological problems: Scepticism, Gettier, and the lottery', Australasian Journal of Philosophy, 76 (2), 289-306.

--- (2013), 'Contextualism defended', in Matthias Steup, John Turri, and Ernest Sosa (eds.), Contemporary Debates in Epistemology (2; Malden, Mass: WileyBlackwell), 69-75.

DeRose, Keith (2002), 'Assertion, knowledge, and context', The Philosophical Review, $111(2), 167-203$. 
--- (2005), 'The Ordinary Language Basis for Contextualism, and the New Invariantism', The Philosophical Quarterly, 55 (219), 172-98.

--- (2009), The case for contextualism (Oxford: Oxford University Press).

--- (2011), 'Contextualism, contrastivism, and X-Phi surveys', Philosophical Studies, 156 (1), 81-110.

Dinges, A (2015), 'Epistemic invariantism and contextualist intuitions', Episteme, FirstView, 1-14.

Fantl, Jeremy and McGrath, Matthew (2009), Knowledge in an Uncertain World (Oxford University Press).

Feltz, Adam and Zarpentine, Chris (2010), 'Do You Know More When It Matters Less?', Philosophical Psychology, 23 (5), 683-706.

Gerken, Mikkel (2013), 'Epistemic Focal Bias', Australasian Journal of Philosophy, 91 (1), $41-61$.

--- (Forthcoming), On Folk Epistemology (University of Edinburgh).

Hannon, Michael (this volume), 'Contextualism and Skepticism ', in Jonathan Ichikawa (ed.), Handbook of Epistemic Contextualism (Routledge).

Hansen, Nat (2014), 'Contrasting Cases', in James Beebe (ed.), Advances in Experimental Epistemology (Bloomsbury), 71-95.

Hansen, Nat and Chemla, Emmanuel (2013), 'Experimenting on Contextualism', Mind and Language, 28 (3), 286-321.

Hawthorne, John and Stanley, Jason (2008), 'Knowledge and action', Journal of Philosophy, 105 (10), 571. 
Kuhn, Thomas (1962), The Structure of Scientific Revolutions, 2 vols. (2: The University of Chicago Press).

Laudan, L and Leplin, J (1991), 'Empirical Equivalence and Underdetermination', Journal of Philosophy, 88, 449-72.

Lewis, David (1979), 'Scorekeeping in a language game', Journal of Philosophical Logic, $8(1), 339-59$.

--- (1996), 'Elusive knowledge', Australasian Journal of Philosophy, 74 (4), 549-67.

May, Joshua, Sinnott-Armstrong, Walter, Hull, Jay G., and Zimmerman, Aaron (2010), 'Practical Interests, Relevant Alternatives, and Knowledge Attributions: An Empirical Study', Review of Philosophy and Psychology, 1 (2), 265-73.

Nagel, Jennifer (2010), 'Knowledge ascriptions and the psychological consequences of thinking about error', The Philosophical Quarterly, 60 (239), 286-306.

Pinillos, N. Ángel (2012), 'Knowledge, Experiments and Practical Interests', in Jessica Brown and MIkkel Gerken (eds.), New Essays On Knowledge Ascriptions (Oxford University Press), 192-219.

Powell, Derek, Horne, Zachary, Pinillos, Ángel, and Holyoak, Keith (2015), 'A Bayesian framework for knowledge attribution: Evidence from semantic integration', Cognition, 139, 92-104.

Quine, W. V. (1955), 'Posits and Reality', The Ways of Paradox and Other Essays (Cambridge, MA: Harvard University Press), 246-54.

Rysiew, Patrick (2011), 'Contextualism', Stanford Encylopedia of Philosophy.

Schaffer, Jonathan and Knobe, Joshua (2012), 'Contrastive knowledge surveyed', Nous, $46(4), 675-708$. 
Turri, J (2014), 'Skeptical Appeal: The Source - Content Bias', Cognitive Science, 38 (5), $307-24$.

--- (2016), 'Epistemic Contextualism: An Idle Hypothesis', Australasian Journal of Philosophy

Turri, J and Buckwalter, W (Forthcoming), 'Descartes's Schism, Locke's Reunion: Completing the Pragmatic Turn in Epistemology', American Philosophical Quarterly.

Turri, J, Buckwalter, W, and Rose, D (2016), 'Actionability judgments cause knowledge judgments', Thought, 5 (3), 212-22.

Turri, John and Friedman, Ori (2014), 'Winners and losers in the folk epistemology of lotteries', in J R Beebe (ed.), Advances in experimental epistemology (Bloomsbury), 45-70.

Waterman, John, Gonnerman, Chad, Yan, Karen, and Alexander, Joshua (in press), 'Knowledge, Certainty, and Skepticism: A Cross-Cultural Study', in E McCready, et al. (eds.), Epistemology for the Rest of the World (Oxford University Press). 